Lingua e Literatura, $n^{\circ} 24$, p. 121-130, 1998.

\title{
LIINGUAS MINORITÁRIAS ENTRE O SIMBÓLICO E O POLÍTICO: O CASO DO CRIOULO NAS ANTILHAS FRANCESAS
}

\author{
Véronique Dahlet*
}

\begin{abstract}
RESUMO: Línguas minoritárias e lingua dominante veicular quase sempre coexistem de maneira problemática, senāo abertamente conflitual. Baseando-nos no caso das Antilhas, gostariamos de mostrar como uma intervençāo política - $a$ institucionalizaçāo do crioulo através de seu ensino-poderia contribuir à reincorporaçāo do eu no sujeito francófono-crioulófono. A clara consciência desta cisão do eu em determinados inteletuais, escritores e professores universitários antilhanos, levou à criaçāo do conceito de crioulidade, verdadeira carta universal dos direitos das comunidades à identidade lingüística e cultural, concebida, porém, dentro da impregnaçāo do Outro e da abertura ao Diverso. Perguntamonos, em seguida, se, no contexto da globalizaçāo, a política lingüística francesa - mas também européia, nāo se orienta na direçāo trilhada pelo conceito de crioulidade, e em que medida isto nāo favoreceria, de maneira reflexiva, a aceitaçāo da institucionalizaçāo do crioulo.
\end{abstract}

Palavras-chave: diglossia, simbólico, política, crioulidade,crioulo.

As línguas não servem apenas para comunicar. Elas sāo ainda a expressāo mais elevada de nossa subjetividade e o espaço por excelência onde se elabora nossa identidade individual e coletiva. Somos menos usuários de uma

(*) Professora do Departamento de Letras Modernas, FFLCH-USP. 
lingua do que habitados por ela. Entretanto, as línguas são também formatadas pelas vontades ou pelos conflitos políticos, econômicos e culturais.

A situação de diglossia nas Antilhas francesas poderia talvez, num futuro próximo, modificar os equilibrios vigentes. Com efeito, a Universidade das Antilhas e da Guiana pretende solicitar ao Ministério de Educaçāo Nacional francês a criaçāo de um novo concurso, o concurso da lingua crioula, que ocuparia entāo seu lugar ao lado dos concursos nacionais já existentes para as disciplinas estabelecidas (Letras Modernas ou Clássicas, Matemática, etc.). Na hipótese de o Ministério se pronunciar favoravelmente à implantação do concurso da lingua crioula, a Faculdade de Letras e Ciências Humanas, sediada na Martinica, abriria um curso preparatório de um ano, após a licenciatura em Letras, destinado a formar futuros professores de crioulo. Através da institucionalizaçāo da língua crioula, os atores desse gesto político visam em primeiro lugar a uma territorialização da identidade crioula, mas concebida em sua abertura ao mundo: ao mesmo tempo desejo e desafio compreensiveis quando sabemos que dois desses atores universitários são também, junto com o escritor Patrick Chamoiseau, os co-autores do Elogio da crioulidade. Mas a institucionalização de uma língua com forte tradição oral e fraca tradição escrita não deixa de criar problemas. Evocarei mais adiante algumas dessas dificuldades. Podemos nos perguntar se e em que medida essa possivel nova configuração do quadro, ou seja, o fato de que pela primeira vez as duas linguas em contato, o francês e o crioulo, serão simultaneamente objeto de análise $e$ de representaçāo, irá modificar, com o decorrer do tempo, o corte simbólico do sujeito em situação diglóssica. Evidentemente, é impossivel responder a essas questões sem cair em meras conjeturas. Acredito, no entanto, que o conceito de crioulidade, que integra mas ultrapassa amplamente essa questão, fornece ao debate sobre as minorias lingüísticas dois eixos fundamentais de reflexão e um esquema de aná- 
lise dos mais pertinentes, debate que, no contexto da globalização, ganha sempre mais acuidade.

1. Nas Antilhas, o crioulo nasceu de uma situaçāo histórica precisa e sobredeterminada: o sistema escravagista. De um lado, os senhores brancos de língua francesa; de outro, os negros, que aliás nem sequer se entendiam entre eles, porque deportados de diferentes regiōes da África. A partir de entāo, bem ou mal coexistem nas Antilhas francesas as duas linguas: o francês e o crioulo ${ }^{1}$ Estamos, portanto, em estado de diglossia, mas em paridade bastante desigual, pois o francês é aí a língua veicular, e como tal vigora no conjunto dos setores públicos - administrativo, comercial, educativo, cultural -, enquanto o crioulo, língua vernácula, é reservado aos intercâmbios privados ${ }^{2}$ Numa tal distribuição lingüistica, cultural e política, a situação de equilíbrio entre os dois pólos está logo de início bloqueada. O dominio esmagador de uma língua sobre a outra induz, como ocorre freqüentemente, a conflitos mais ou menos violentos que só resoluções políticas podem resolver.

Dentro dessa perspectiva, a introdução do ensino da lingua crioula pode ser percebida como um gesto político positivo, uma vez que ela será institucionalizada. Mas para que uma língua se torne objeto de um ensino reconhecido em âmbito nacional, é preciso que ela seja na escrita uma lingua constituida, fixada - e sabemos bem que a escrita constitui o "núcleo duro" de uma língua. Ora, não é o caso do crioulo, de forte tradição oral. Mencionarei aqui três pontos de resistência a sua institucionalização, e sobre os quais será preciso agir para que o ensino do crioulo seja implantado.

(1) Haiti e a Guiana Francesa conhecem situaçōes lingüísticas diferentes. Por isso, me limitarei especificamente à Martinica e à Guadalupe.

(2) Para uma análise do mapa lingüístico das Antilhas francesas, cf. Bernabé (1983), “Le cadre anthropolinguistique" p. 19-79. 
a) O crioulo não está representado na imprensa de informação - plano sociopolítico - e muito pouco na literatura antilhana - plano sociocultural - ${ }^{3}$ Isso significa que o fundo escritural, já pouco considerável, não dá no momento nenhum sinal de desenvolvimento ou de renovação: daí decorre o perigo real de tornar-se uma lingua escrita "de museu"

b) Se a língua foi o objeto de descriçōes científicas há gramáticas de referência -, resta fazer ajustes, especialmente no que diz respeito à pontuação. Com efeito, a pontuação foi quase diretamente transferida do sistema francês, o que não pode evidentemente ser adequado, quando sabemos que a pontuação opera ao mesmo tempo sobre a sintaxe e sobre o ritmo e que ambos são radicalmente diferentes no francês e no crioulo. Assim, tratar-se-ia de estabelecer convenções que teriam naturalmente de levar em conta os componentes sintáticos, morfológicos, semânticos e ritmicos próprios do crioulo escrito.

c) O terceiro ponto diz respeito ao capital lexical. Sabemos que os conhecimentos científicos contemporâneos nascem e evoluem na escrita e através da escrita. Isso significa que nesse fim de século XX, por razões conjunturais, o capital lexical do crioulo acompanhou de modo bastante desigual os progressos ou descobertas e conseqüentemente não dispõe de muitos paradigmas lexicais suscetiveis de formulá-los e, a fortiori, de produzi-los ${ }^{4}$ Mais uma vez, aquilo que está em jogo na ótica do ensino é de importância considerável, na medida em que se trata de fornecer à lingua crioula os meios de tornar-se lingua conceitual.

2. As resistências lingüisticas, mas também didáticas, se elas merecem ser levadas a sério para não correr o risco de um fracasso a curto prazo, não podem, no entanto, justificar que se renuncie ao ensino do crioulo, ou seja, ao

(3) O caso de Raphaël Confiant se interpreta como um sintoma: seus seis primeiros romances foram publicados em crioulo, mas, por falta de leitores e, portanto, de reconhecimento na cena litérária, ele escolheu/viu-se obrigado a escrever em francês.

(4) Para uma análise de "diglossia lexical" ver L'éloge de la muette de J. Coursil (1996). 
seu reconhecimento institucional (Cf. A. Lucrèce, 1981). Enumerarei rapidamente alguns pontos significativos:

a) a lingua serve certamente para que nos comuniquemos, mas não podemos ignorar sua dimensão cognitiva e afetiva. Se nos restringirmos ao âmbito da escola, podemos nos perguntar se o ensino, nas Antilhas francesas, não estaria lá há quase um século fracassando na sua missão educativa. Com efeito, não haveria um dilaceramento dífícil de ser vivido entre a língua vernácula, feita para seus pares comungarem e a língua veicular que é também a que é ensinada?

$\mathrm{Na}$ verdade, essa mesma questão se desdobra ao infinito, recorrência que demonstra, se necessário, "o direito à educação em sua própria língua":

"Se a língua [no caso, o crioulo] penetra até no domínio do sonho, como excluí-la do campo da aprendizagem escolar?" (Y. Déjean, citado por A. Lucrèce, 1981, p. 223).

"O individuo se constitui sujeito na e pela lingua [...]. $O$ sujeito fala francês, mas sua identificação é crioula" (J. Coursil, 1996, p. 222).

$\mathrm{O}$ escritor $\mathrm{P}$ Chamoiseau, em seu livro tão pertinentemente intitulado Écrire en pays dominé, expōe o dilema diglóssico da escritura poética:

"Como escrever quando seu imaginário se embebe, de manhā até os sonhos, na fonte das imagens, dos pensamentos, de imagens, de pensamentos, de valores que não são os seus? Como escrever quando aquilo que você é vegeta fora dos impulsos que determinam sua vida?" (1997. p. 17).

Vemos que quaisquer que sejam as perspectivas através das quais a questão da diglossia é abordada, a análise chega invariavelmente à divisão que fundamenta o locutor 
antilhano. Entretanto, no âmbito lingüístico, seria redutor pensar que o francês e o crioulo coexistem na simples contigüidade, ou seja, sem se impregnarem um do outro. Assistimos hoje em dia, tanto à crioulização do francês quanto ao afrancesamento do crioulo: "a competência lingüística da maioria dos que têm o sentimento de falar francês vs crioulo [ou crioulo us francês] é uma competência amplamente interlectal" (Bernabé, 1982, p. 26). O fato de "a intertextualidade se tornar uma condição essencial da enunciação antilhana" (id., ibid.) poderia se reduzir a uma simples constatação lingüistica. Parece-me essencial, entretanto, notar que as próprias condições que possibilitam esse observável exprimem claramente a visão interétnica e intercultural subjacente ao conceito de crioulidade.

3. O que hoje em dia está ameaçado no mundo "é nāo somente a legitimidade das culturas (a vivacidade dos povos), mas também a de sua relaçāo de 'equivalência' " Da constataçāo de E. Glissant (1990, p. 67) decorrem duas propostas:

a) a legitimidade das culturas, ou seja, o pleno gozo de sua expressāo. $O$ ensino da lingua crioula representa a vertente predominante, no meu entender, da legitimidade da cultura crioula, tanto no âmbito institucional quanto simbólico (cf. supra). A simples proclamação do crioulo como lingua institucional faz com que ele seja considerado legítimo. O mesmo nāo acontece com o simbólico, ao qual a palavra legitimação, ou seja, a entrada no processo de legitimidade, conviria melhor, pois resta ainda aos locutoressujeitos crioulos aderirem a si mesmos, pensarem-se a partir de um centro-eu e não mais de um centro longinquo exterior - a França hexagonal - que funda todos os schizos. Mas passar de uma identidade por procuração a uma identidade autêntica, incorporada, pede em primeiro lugar aceitar a si próprio, desfazer-se da autodifamaçāo, durante mui- 
to tempo dominante na representação que a maioria dos Antilhanos tinha e ainda tem muito freqüentemente de si mesmos. Processo lento e dificil, quando estamos apoiados em três séculos de escravagismo, seguidos de dominação. “O afrancesamento nos forçou à autodifamação, destino comum dos colonizados" djzem os autores de L'éloge de la créolité (p. 24). Podemos esperar que a legitimidade institucional do crioulo impulsionará sua legitimação simbólica.

b) a relação de equivalência das culturas

O espirito da crioulidade não se parece em nada com uma reivindicação de identidade regional que se alimentaria da rejeiçāo maciça e rancorosa do outro, da diferença, muito pelo contrário. Partindo da constataçāo de que a história e a antropologia das Caraíbas são feitas do "agregado internacional ou transacional dos elementos culturais caribenhos, europeus, africanos, asiáticos e levantinos" (Eloge de la créolité, p. 26), a crioulidade pensa sua própria raiz no modo da Relação (Glissant). O conceito de crioulidade não é de ordem geográfica, mas da ordem da antropologia lingüística, definindo as configuraçōes políticas e econômicas cujo ponto de partida é radicalmente bilingüe, senão multilíngüe. Constitutivamente, trata-se, pois, para todo locutor, de falar a sua lingua ou suas linguas não só para constituir sua identidade, mas para dizer sua relação com o mundo (Poética, Glissant, p. 122), no reconhecimento e no respeito do outro, que não é eu, mas que entretanto me determina ao mesmo tempo em que eu o determino.

$O$ que nesse contexto me parece digno de ser ressaltado é o conceito de francofonia que há cerca de 10 anos trilha o mesmo caminho. Não há dúvida de que a gênese histórica da crioulidade e da francofonia nāo sāo comparáveis. A emergência da francofonia não é um conceito e uma politica lingüistica nascidos isoladamente: eles se situam efetivamente num contexto mais amplo, atualmente na ordem do dia e que é o plurilingüismo. O plurilingüismo é um 
vetor de ação, é uma urgência politica, cultural e direi mesmo democrática ${ }^{5}$ Nāo se trata simplesmente de lutar, no tabuleiro dos mercados das linguas, contra o inglês, língua dominante de comunicação internacional; trata-se essencialmente de lutar pela pluralidade lingüistica e cultural, cada dia não apenas ameaçada mas realmente em recesso diante "do risco maior da uniformização induzida pelo desenvolvimento das tecnologias que favorecem a globalizaçāo das trocas e da comunicação" (A. Juppé, 1996, p.73).

Se mencionei esse contexto de estratégia do plurilingüismo (que apaga o bilingüismo cuja permanência favoreceria inevitavelmente a hegemonia americana), é porque me parece que ela influenciou no bom sentido a politica francesa no próprio seio de suas minorias lingüísticas, sob o duplo efeito dos riscos trazidos pela globalização, de um lado, e de outro, pela construçāo da Comunidade Européia que exigiu uma abertura para as outras linguas européias. Essas duas realidades - globalização e CE (Comunidade Européia) modificaram profundamente a representação que as elites francesas - financeira, politica, diplomática e cultural - tinham da própria lingua.

A defesa das linguas, diz E. Glissant, garantia do $D i-$ verso, é inseparável do reequilibrio das relações entre as comunidades. O ensino do crioulo nas escolas das Antilhas francesas constituirá, se for ratificado, um sinal dessa reequilibração.

Tradução: Maria Sabina Kundman

(5) Neste contexto, o IX Congresso Mundial da Federação Internacional dos Professores de Francês (Tokio, agosto de 1996), cujo tema foi, de maneira significativa, "Tracer l'avenir, cultiver la différence", engajou-se no "pluralisme culturel et linguistique face au défi de l'uniformisation, à l'émergence des grands ensembles continentaux. aux revendixations identitaires et à la montée des nationalismes" 


\section{BIBLIOGRAFIA}

BERNABÉ, J.; CHAMOISEAU, P.; CONFIANT, R. Éloge de la créolité. Paris, Gallimard, 1989.

BERNABÉ, J.Espace sociolinguistique et espace sociolittéraire antillais. In: L'écrit et l'oral. Littératures et contacts de culture. Paris, L'Harmattan, vol.1, 1982.

. Fondal-natal. Grammaire basilectale approchée des créoles guadeloupéen et martiniquais. Paris, L'Harmattan, 3 vol., 1983.

CHAMOISEAU, P. Écrire en pays dominé. Paris, Gallimard, 1997 COURSIL, J.L'éloge de la muette. In: La commotion des langues. Paris, Césure, Revue de la Convention psychanalytique, décembre, 1996.

GLISSANT, E. Poétique de la Relation. Paris, Gallimard, 1990. JUPPÉ, A.Pour la défense d'un monde pluriel. Le Monde de l'Education, $\mathrm{n}^{\circ}$ 239, 1996.

LUCRĖCE, A. Civilisés et énergumènes. De l'enseignement aux Antilles. Paris, L'Harmattan, 1981.

ABSTRACT: Minority languages and the dominant vehicular language coexist almost always in a problematic, if not in an openly conflicting way. Basing our investigation on the case of the French Antilles, we would like to demonstrate how political intervention - institutionalizing Creole by teaching it - could contribute to the reincorporation of the I, of the French-speaking-Creole-speaking subject. The clear consciousness of this splitting of the I experienced by certain Antillean intellectuals, writers and university professors, led to the creation of the concept of creolity, a real universal chart of the communities'rights to enjoy their linguistic and cultural identity, conceived, however, within the permeation of the Other and the openess towards the Diverse. Furthermore we wonder whether, in the context of globalization, the French linguistic politics, but the European just as well, does 
130 DAHLET, Véronique. Linguas minoritárias entre o simbólico e o político: o caso do crioulo nas Antilhas Francesas

not head for the way beaten by the concept of creolity and how far this would not, in return, foster the acceptance of Creole's institutionalization.

Keywords: diglossia, symbolic, politics, creolity, Creole. 